\title{
Bitlis'te Yetişen Bazı Tıbbi ve Aromatik Bitkilerin Radyo İzotop Aktivite Konsantrasyonları
}

\author{
Sultan ŞAHIN BAL ${ }^{1 *}$, Fikriye GÖNÜLTAŞ ${ }^{1}$, Önder KILIÇ ${ }^{1}$, Murat KURŞAT $^{2}$, Ayşegül \\ DEMIR YETIŞ̧
}

\author{
${ }^{1}$ Bitlis Eren Üniversitesi, Fizik Bölümü, Bitlis \\ ${ }^{2}$ Bitlis Eren Üniversitesi, Biyoloji Bölümü, Bitlis \\ ${ }^{1}$ Bittis Eren Üniversitesi, Çevre Mühendisliği Bölümü, Bitlis \\ (ORCID: 0000-0001-7896-0771) (ORCID:0000-0002-8514-7399) (ORCID:0000-00018948-3413)
}

(ORCID:0000-0002-0861-4213) (ORCID:0000-0003-4745-2445)

\section{$\ddot{\mathbf{O} z}$}

Bu çalışmada, Bitlis'te yetişen bazı bitkilerde doğal olarak bulunan radyo izotop konsantrasyon seviyeleri belirlendi. Numuneler, $\mathrm{NaI}(\mathrm{Tl})$ gama 1 şını spektrometresi kullanılarak analiz edildi. Bu bitkilerde, ${ }^{226} \mathrm{Ra}$ radyo izotop aktivite konsantrasyon seviyelerinin $12,45 \pm 2,53 \mathrm{~Bq} / \mathrm{kg}$ ile $92,08 \pm 5,34 \mathrm{~Bq} / \mathrm{kg}$ arasında, ${ }^{232} \mathrm{Th}$ radyo izotop konsantrasyon seviyelerinin $23,10 \pm 4,42 \mathrm{~Bq} / \mathrm{kg}$ ile $88,00 \pm 6,68 \mathrm{~Bq} / \mathrm{kg}$ arasinda, ${ }^{40} \mathrm{~K}$ radyo izotop konsantrasyon seviyelerinin $42,57 \pm 5,15 \mathrm{~Bq} / \mathrm{kg}$ ile $533 \pm 7,78 \mathrm{~Bq} / \mathrm{kg}$ arasında değiştiği görülmüştür.

Anahtar kelimeler: Tıbbi ve Aromatik Bitkiler, Radyo Çekirdek, Bitlis.

\section{The Radioisotope Activity Concentrations of Some Medical and Aromatic Plants Growing in Bitlis}

\begin{abstract}
In this study, the levels of radioisotope activity concentration naturally found in some plants growing in Bitlis were determined. The samples are analyzed using $\mathrm{NaI}(\mathrm{Tl})$ gamma ray spectrometry. In these plants, it is seen that the levels of ${ }^{226} \mathrm{Ra}$ radioisotope activity concentration between $12.45 \pm 2.53 \mathrm{~Bq} / \mathrm{kg}$ and $92.08 \pm 5.34 \mathrm{~Bq} / \mathrm{kg}$, the levels of ${ }^{232} \mathrm{Th}$ activity concentration between $23.10 \pm 4.42 \mathrm{~Bq} / \mathrm{kg}$ and $88.00 \pm 6.68 \mathrm{~Bq} / \mathrm{kg}$, the levels of ${ }^{40} \mathrm{~K}$ radioisotope activity concentration between $42.57 \pm 5.15 \mathrm{~Bq} / \mathrm{kg}$ and $533.48 \pm 7.78 \mathrm{~Bq} / \mathrm{kg}$ are changed.
\end{abstract}

Keywords: Medicinal and Aromatic Plants, Radioisotope, Bitlis.

\section{Giriş}

Doğal radyo-çekirdekler, dünyanın oluşumundan bu yana; dünyanın bileşenleri olmuştur ve dünya ortamında doğal olarak yayılmıştır. Doğal ortamda, uranyum ve toryum serisine ait radyoizotoplar ve ${ }^{40} \mathrm{~K}$ içeren birçok doğal olarak oluşan radyo-çekirdek vardır. Bu doğal radyo-çekirdekler toprakta, tortuda, suda, bitkilerde ve havada bulunur. Çevresel radyoaktivite ve gama radyasyonu nedeniyle; dış kaynaklı radyasyona maruz kalma, temel olarak dünyadaki her bir bölgenin jeolojik koşullarına, toprak ve sediment oluşumlarına bağlıdır $[1,2]$.

Herhangi bir bölgenin jeolojik ve coğrafi koşulları; radyo-çekirdek konsantrasyonunun seviyesini etkileyerek, farklı kısa ve uzun ömürlü radyo-çekirdeklerin dünyanın biyo-matrislerini kirletmesine neden olur $[3,4]$.

Canlı organizmalar genellikle doğal veya insan yapımı kaynaklardan yayılan arka plan (background) radyasyona sürekli olarak maruz kalırlar. Radyasyonun etki türleri deterministik ve

"Sorumlu yazar: sahin.sultan@gmail.com

Geliş Tarihi: 28.10.2019, Kabul Tarihi: 19.12.2019 
stokastik etkilerdir. Canlı organizmalara radyasyondan gelen etkiler; genellikle stokastik etki kategorisine girer [5].

Geleneksel olarak genellikle şifa bulmak ya da tatlandırmak amacıyla kullanılan şifalı bitkiler; radyoaktif içerikleri açısından incelenen yenilebilir bitkiler grubuna dahil edilmez, çünkü tüketimlerinden dolayı doğrudan radyoaktif madde alımı önemsiz kabul edilmiştir. Yüksek konsantrasyonlarda doğal radyo-çekirdek içeren bir şifalı bitki, uzun süre boyunca yaygın olarak kullanıldığında sağlık sorunlarına neden olabilir [6].

Bu çalışmada, Bitlis bölgesinde yetişen, genellikle tatlandırıcı ve şifa bulmak amacıyla sıkça tüketilen bazı bitki örneklerinin radyoaktivite konsantrasyon seviyeleri tespit edilmiştir.

\section{Materyal ve Metot}

\subsection{Bitlis' in Genel Jeolojisi}

Bitlis Metamorfik kuşağı boyunca çeşitli stratigrafik kesitler mevcuttur. Asidik karakterli magma çıkışları, granit, granitik gnayslar, andezitler, dasitler ile bazik karakterli bazaldik lavlar bulunmaktadır (Şekil 1) [7].
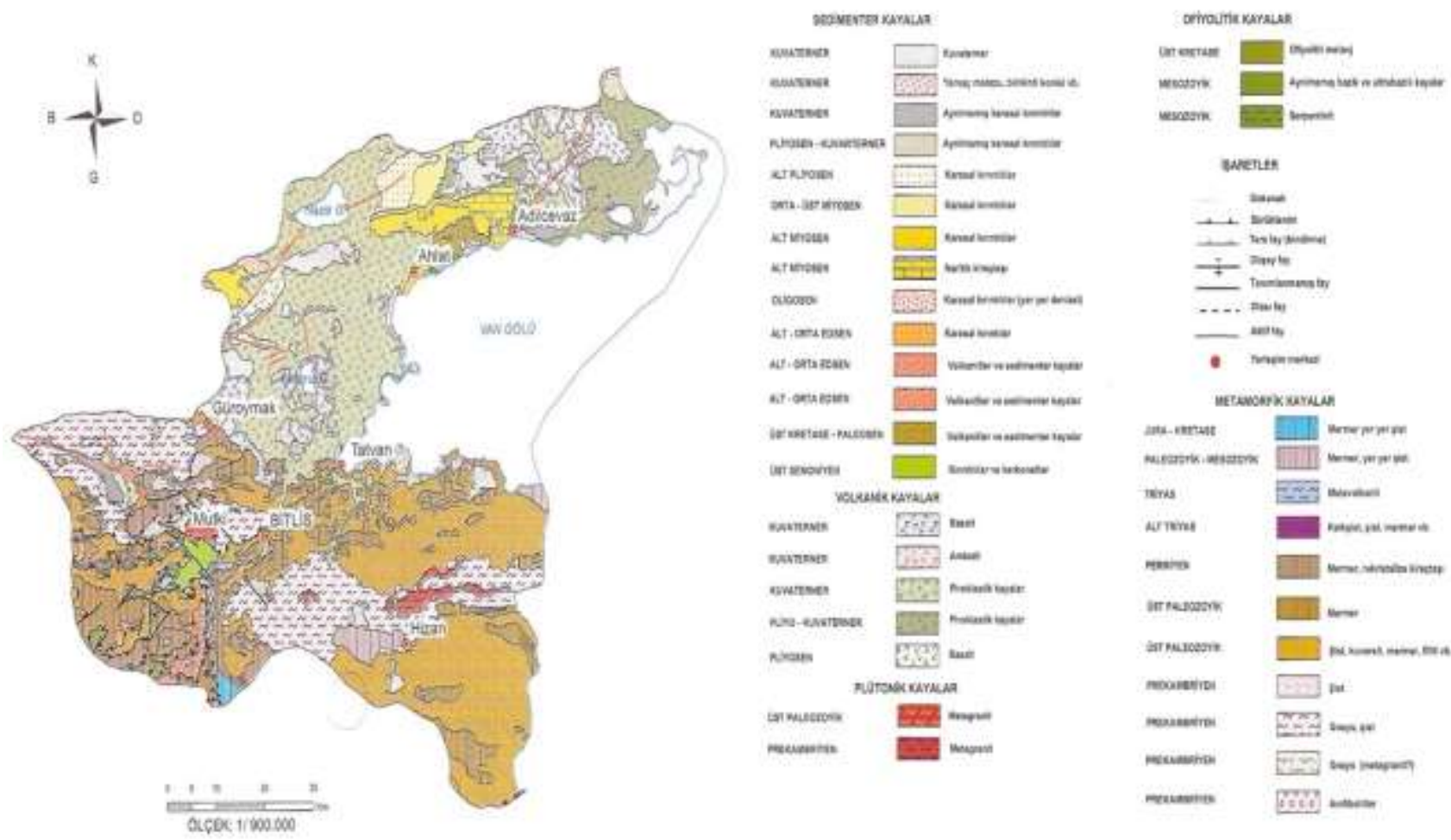

Şekil 1. Bitlis' in jeolojik haritası

\subsection{Aktivite Ölçümleri}

Tamamen nemden arındırmak amacıyla, bitki örnekleri alüminyum folyalara sarıldı ve $80{ }^{\circ} \mathrm{C}$ de etüv içerisinde yaklaşık 24 saat bekletildi. Örnek kapları içine konulan bitki örnekleri, yaklaşık 30 gün boyunca radyoaktif dengenin sağlanması için bekletildi.

Örnekler, ORTEC marka 3x3-inç boyutunda kristal Talyum (TI) katkılı NaI sintilatörlü, 0,5 $\mathrm{MeV}$ de $\% 2$ ve $2 \mathrm{MeV}$ de \% 1,3 verime sahip gama detektöründe 86400 s sayıldı. Bitki örneklerinin analizinde ${ }^{226} \mathrm{Ra}$ aktivitesi için; ${ }^{214} \mathrm{Bi}$ 'nin $609,312 \mathrm{keV}$ 'lik fotopiki kullanılmıştır. ${ }^{232} \mathrm{Th}$ aktivitesi için; ${ }^{228} \mathrm{Ac}$ 'nin $911,205 \mathrm{keV}$ 'lik fotopiki kullanılmıştır. ${ }^{40} \mathrm{~K}$ aktivitesi için ise $1461,83 \mathrm{keV}$ 'lik fotopik kullanılmıştır. Aşağıdaki denklem kullanılarak aktivite hesabı yapılmıştır $[8,9]$. 
$A=\frac{C}{\varepsilon \times t \times M}$

Yukarıdaki denklemde; A, radyoizotop konsantrasyonu $(\mathrm{Bq} / \mathrm{kg}), \mathrm{C}$, net pik alanı (sayım), $\varepsilon$, verim, t, sayım süresi (86400 s), M, numune kütlesidir (kg).

\section{Bulgular ve Tartışma}

Şifalı bitki örneklerinin ${ }^{226} \mathrm{Ra},{ }^{232} \mathrm{Th}$ ve ${ }^{40} \mathrm{~K}$ radyo-çekirdek aktivite konsantrasyonları Tablo 1'de verilmiştir. Şifalı bitki örneklerinin, ${ }^{226}$ Ra radyo-çekirdek aktivite konsantrasyonun; $12,45 \pm 2,53 \mathrm{~Bq} / \mathrm{kg}$ (B01) ile $92,08 \pm 5,34 \mathrm{~Bq} / \mathrm{kg}$ (B03) arasında, ${ }^{232} \mathrm{Th}$ radyo-çekirdek aktivite konsantrasyonun 23,10 \pm $4,42 \mathrm{~Bq} / \mathrm{kg}$ (B11) ile 88,00 $\pm 6,68 \mathrm{~Bq} / \mathrm{kg} \quad$ (B04) arasında, ${ }^{40} \mathrm{~K}$ 'ın ise radyo-çekirdek aktivite konsantrasyonun; 42,57 $\pm 5,15 \mathrm{~Bq} / \mathrm{kg}$ (B07) ile 533,48 \pm 7,78 Bq/kg (B12) değerleri arasında değiştiği görülür.

Tablo 1. Bazı tıbbi ve aromatik bitki örneklerinin ${ }^{226} \mathrm{Ra}$, ${ }^{232} \mathrm{Th}$ ve ${ }^{40} \mathrm{~K}$ radyo-çekirdek aktivite konsantrasyonları

\begin{tabular}{cccccc}
\hline Numune & Numune Adı & Lokasyon & ${ }^{226} \mathrm{Ra}(\mathrm{Bq} / \mathrm{kg})$ & ${ }^{232} \mathrm{Th}(\mathrm{Bq} / \mathrm{kg})$ & ${ }^{40} \mathrm{~K}(\mathrm{~Bq} / \mathrm{kg})$ \\
\hline B01 & Sarı civanperçemi & Tatvan & $12,45 \pm 2,53$ & $48,57 \pm 6,76$ & $252,26 \pm 5,19$ \\
B02 & Boz otu & Tatvan & $41,06 \pm 1,81$ & $66,17 \pm 3,65$ & $413,00 \pm 6,39$ \\
B03 & Isırgan otu & Tatvan & $92,08 \pm 5,34$ & $63,21 \pm 2,81$ & $469,84 \pm 7,59$ \\
B04 & Deve dikeni & Tatvan & $74,74 \pm 3,87$ & $88,00 \pm 6,68$ & $451,07 \pm 6,40$ \\
B05 & Şirker & Tatvan & $38,99 \pm 2,22$ & $74,40 \pm 6,89$ & $147,18 \pm 4,13$ \\
B06 & Kekik & Tatvan & $35,44 \pm 1,74$ & $59,77 \pm 3,72$ & $308,82 \pm 5,85$ \\
B07 & Boz otu & Tatvan & $42,71 \pm 2,05$ & $46,95 \pm 3,39$ & $42,57 \pm 5,15$ \\
B08 & Yabani tere & Tatvan & $32,34 \pm 4,36$ & $41,10 \pm 1,91$ & $323,63 \pm 5,52$ \\
B09 & Gelincik & Ahlat & $51,54 \pm 2,25$ & $75,11 \pm 3,99$ & $398,34 \pm 5,97$ \\
B10 & Sar1 civanperçemi & Adilcevaz & $34,09 \pm 1,44$ & $66,74 \pm 4,75$ & $432,75 \pm 6,63$ \\
B11 & Pitrak & Güroymak & $59,93 \pm 3,01$ & $23,10 \pm 4,42$ & $439,75 \pm 6,59$ \\
B12 & Taş turşusu & Güroymak & $23,26 \pm 5,37$ & $65,87 \pm 3,05$ & $533,48 \pm 7,78$ \\
B13 & Sarı civanperçemi & Ahlat & $18,88 \pm 1,08$ & $36,81 \pm 4,70$ & $253,72 \pm 4,65$ \\
\hline
\end{tabular}

Şekil 2 incelendiğinde; ${ }^{40} \mathrm{~K}$ radyo-çekirdek aktivite konsantrasyonlarının, ${ }^{226} \mathrm{Ra}$ ve ${ }^{232} \mathrm{Th}$ radyoçekirdek aktivite konsantrasyonlarından fazla olduğu görülmektedir. B07 numaralı bitki örneğinde, her üç radyo-çekirdek aktivite konsantrasyonunun hemen hemen aynı değere sahip olduğu görülmektedir. B03 ve B11 numaralı bitki örneklerinde, ${ }^{226} \mathrm{Ra}$ radyo-çekirdeği aktivite konsantrasyonunun ${ }^{232} \mathrm{Th}$ radyoçekirdek aktivite konsantrasyonundan fazla olduğu görülmektedir. Diğer bitki örneklerinde, ${ }^{232} \mathrm{Th}$ radyo-çekirdek aktivite konsantrasyonları ${ }^{226} \mathrm{Ra}$ radyo-çekirdek aktivite konsantrasyonlarından daha fazladır.

Bu çalışmada tespit edilen radyo-çekirdek aktivite konsantrasyonları, literatürde yapılan benzer çalışmalar (Tablo 2) ile karşılaştırıldığında; Radyum ve Toryum radyoaktivite konsantrasyon değerlerinin diğer çalışmalarda tespit edilen değerlerin çok üstünde olduğu görülmektedir. Potasyum radyoaktivite konsantrasyon değerlerinin ise, diğer çalışmalarla hemen hemen aynı değer aralıklarında olduğu görülmektedir. Bitkilerdeki radyoaktivite konsantrasyon değerleri; doğrudan toprak ve sudaki radyoaktivite konsantrasyon seviyelerine bağlıdır. Bununla beraber; bölgenin jeolojik oluşumuna, bitkinin yetiştiği ortamın atmosferik faktörlerine, bitkinin biyolojik ve kimyasal özelliklerine ve daha birçok dış etkene de bağlidır. 


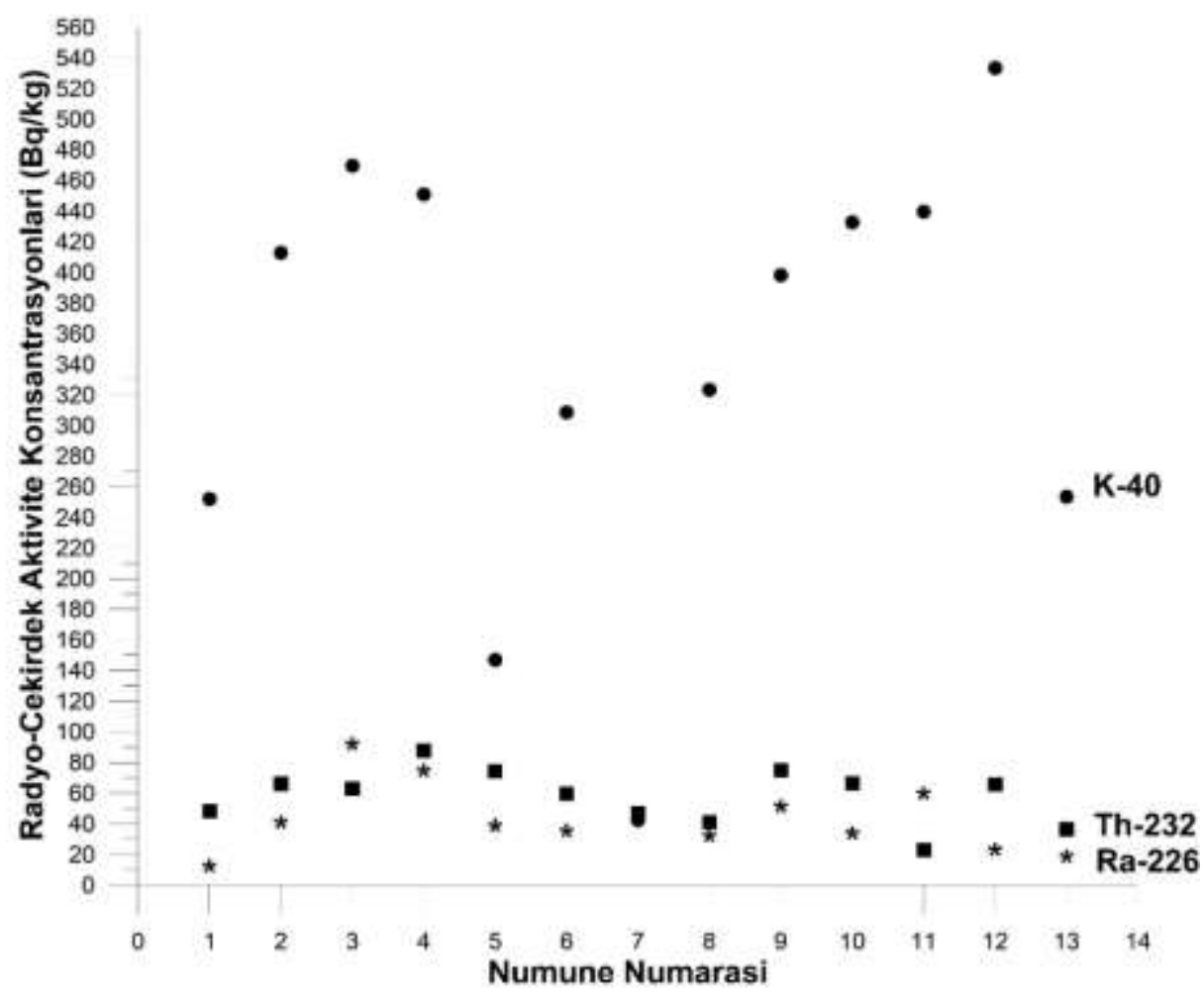

Şekil 2. Bazı tıbbi ve aromatik bitki örneklerinin ${ }^{226} \mathrm{Ra}(*),{ }^{232} \mathrm{Th}(\boldsymbol{\bullet}) \mathrm{ve}^{40} \mathrm{~K}(\bullet)$ radyo-çekirdeklerinin aktivite konsantrasyonlar1

Tablo 2. Literatürdeki bazı çalışma örnekleri [6, 10-13]

\begin{tabular}{ccccc}
\hline Lokasyon & Bitki Türü & ${ }^{226} \mathrm{Ra}(\mathrm{Bq} / \mathrm{kg})$ & ${ }^{232} \mathrm{Th}(\mathrm{Bq} / \mathrm{kg})$ & ${ }^{40} \mathrm{~K}(\mathrm{~Bq} / \mathrm{kg})$ \\
\hline Nijerya & Tibbi & 25,02 & 35,09 & 171,72 \\
Güney Hindistan & Tibbi & 6,34 & 5,05 & 1895,25 \\
Brezilya & Tibbi & 15,85 & 4,35 & - \\
Nijerya & Sebze & 8,75 & 20,13 & 263,88 \\
Malezya & Pirinç & 4,15 & 3,04 & 272,23 \\
Bitlis (Bu çalışma) & Tibbi & 42,89 & 58,14 & 343,57 \\
\hline
\end{tabular}

\section{Sonuç ve Öneriler}

Bu çalışmada, Bitlis’te yetişen 13 tıbbi ve aromatik bitki örneklerinin ${ }^{226} \mathrm{Ra},{ }^{232} \mathrm{Th}$ ve ${ }^{40} \mathrm{~K}$ radyo-çekirdek aktivite konsantrasyonları belirlenmiştir.

(i) B01 (Tatvan), B10 (Adilcevaz) ve B13 (Ahlat) bitki örnekleri aynı tür (Achillea Biebersteinii AfanSarı civan perçemi) bitkilerdir. Bununla birlikte; B02 (Tatvan-Küçüksu Köyü) ve B07 (Tatvan-Han Elmalı Köyü) bitki örnekleri de kendi aralarında aynı tür (Marrubium Parviflorum-Boz otu) bitkilerdir. Fakat, her iki bitki türü örnekleri; farklı radyo-çekirdek aktivite konsantrasyon değerlerine sahiptir.

(ii) Bitki örneklerinin radyoaktivite konsantrasyon değerleri; lokasyona, jeolojik yapıya, bitki türüne, bitkinin kimyasal özelliklerine, bitkinin beslendiği suya vb. faktörlere göre değişmektedir.

(iii) ${ }^{226} \mathrm{Ra}$ ve ${ }^{232} \mathrm{Th}$ radyo-çekirdek aktivite konsantrasyon değerleri literatürdeki benzer çalışmalarda tespit edilen değerlerden daha yüksektir.

(iv) ${ }^{40} \mathrm{~K}$ radyo-çekirdek aktivite konsantrasyon değerleri, literatürdeki benzer çalışmalarda tespit edilen değerler arasındadır.

\section{Kaynaklar}

[1] Aközcan S. 2012. Distribution of Natural Radionuclide Concentrations in Sediment Samples in Didim and Izmir Bay (Aegean Sea-Turkey). Journal of Environmental Radioactivity, 112: 60-63. 
[2] Issa S.A.M., Uosif M.A.M., Tammam M., Elsaman R. 2014. A Comparative Study of the Radiological Hazard in Sediments Samples from Drinking Water Purification Plants Supplied from Different Sources. Journal of Radiation Research and Applied Sciences, 7: 80-94.

[3] UNSCEAR. 2000. Sources and effects of ionising radiation. United Nations Scientific Committee on the Effects of Atomic Radiation., United Nations, New York.

[4] Chandrashekara K., Radhakrishna A.P., Somashekarappa H.M. 2015. Concentration of Natural and Artificial Radionuclides in Mesua Ferea Auct Linn - A Medicinal Plant. Life Sciences International Research Journal, 2 (2): 219-223.

[5] Boumala D., Belafrites A., Tedjani A., Mavon C., Groetz J.E. 2019. Annual Effective Dose and Excess Life Timecancer Risk Assessment from Tobacco plants. Perspectives in Science, 12 (100394): 1-4.

[6] Sussa F.V., Damatto S.R., Alencar M.M., Mazzilli B.P., Silva P.S.C. 2013. Natural Radioactivity Determination in Samples of Peperomia Pellucida Commonly Used as a Medicinal Herb. Journal of Environmental Radioactivity, 116: 148-151.

[7] Işık E. 2010. Bitlis Şehrinin Sismik Performans Analizi. Sakarya Üniversitesi, Fen ve Teknoloji Enstitüsü, Doktora Tezi Sakarya.

[8] Ortec. 2010. Kat1-Hal Dedektörü Kullanma Kilavuzu, USA.

[9] Gönültaş F. 2016. Bitlis’te Yetişen Bazı Tıbbi ve Aromatik Bitkilerde Radyoizotop Aktivite Konsantrasyonlarının Belirlenmesi. Bitlis Eren Üniversitesi, Fen Bilimleri Enstitüsü, Yüksek Lisans Tezi, 52s, Bitlis.

[10] Njinga R.L., Jonah S.A., Gomina M. 2015. Preliminary Investigation of Naturally Occurring Radionuclides in Some Traditional Medicinal Plants Used in Nigeria. Journalof Radiation Research and Applied Sciences, 8: 208-215.

[11] Chandrashekara K., Somashekarappa H.M. 2016. Estimation of Radionuclides Concentration and Average Annual Committed Effective Dose Due to Ingestion for Some Selected Medicinal Plants of South India. Journal of Radiation Research and Applied Sciences, 9: 68-77.

[12] Okeji M.C., Kenneth K.A., Felicitas U.I. 2012. Natural Radioactivity in Cultivated Land in the Vicinity of a Phosphate Fertilizer Plant in Nigeria. Radiation Physics and Chemistry, 81: 18231826.

[13] Alsaffar M. S., Jaafar M. S., Kabir N. A., Ahmad N. 2015. Distribution of ${ }^{226} \mathrm{Ra},{ }^{232} \mathrm{Th}$ and ${ }^{40} \mathrm{~K}$ in Rice Plant Components and Physico-Chemical Effects of Soil on Their Transportation to Grains. Journal of Radiation Research and Applied Sciences, 8: 300-310. 